\title{
Synthesis and Characterization of Iron ${ }^{\mathrm{II}}$, Cobalt ${ }^{\mathrm{II}}$, Nickel $^{\mathrm{II}}$, Copper ${ }^{\mathrm{II}}$, and Zinc ${ }^{\mathrm{II}}$ Complexes Using Diphenylmethyl Xanthate Ligand
}

\author{
Aeed S. Al-Fahdawi ${ }^{1}$ and Eman I. Alsalihi ${ }^{2}$ \\ ${ }^{1}$ Department of Chemistry, College of Education for Women, University of Anbar, Ramadi, Anbar - F.R. Iraq \\ ${ }^{2}$ Department of Chemistry, Faculty of Science and Health, Koya University, Kurdistan Region - F.R. Iraq
}

\begin{abstract}
Potassium diphenylmethyl xanthate and its monomeric complexes were synthesized at room temperature under inert gas and stirring condition. The ligand and its complexes of the general formula $\left[\mathrm{M}(\mathrm{L})_{2}\right]$ (where, $\mathrm{M}=\mathrm{Fe}^{\mathrm{II}}, \mathrm{Co}^{\mathrm{II}}, \mathrm{Ni}^{\mathrm{II}}, \mathrm{Cu}^{\mathrm{II}}, \mathrm{Zn}^{\mathrm{II}}$, and $\mathrm{Cd}^{\mathrm{II}}$ ) were characterized by spectroscopic methods (IR, UV-Vis, ${ }^{1} \mathrm{H}-,{ }^{13} \mathrm{C}-$, DEPT-, HQMC-, and COSY-NMR), elemental analysis, metal content, magnetic susceptibility measurement, and molar conductance. These studies revealed the formation of fourcoordinate complexes.
\end{abstract}

Index Terms-Four-coordinate complexes, Potassium diphenylmethyl xanthate ligand, Structural study, Xanthate complexes.

\section{INTRODUCTION}

Xanthates are an important class of organic species that have shown a range of applications have attracted chemists. This based on their industry applications, analytical, and coordination chemistry. They have been used in industry as flotation agents for nonferrous metal sulfide ore (Coucouvanis, 1979; Rao, 1971). Further, their role as additives lubricating oils is well documented (Rao, 1971). Based on their coordination behavior, xanthates as reagents have been used in analytical determination and separation of a large numbers of metal ions (Exarchos, et al., 2001; Cox, et al., 1996; and Vastag, et al., 1990). Some of xanthates species and their metal complexes are used as pharmaceuticals for HIV infections. Furthermore, xanthate-based gold ${ }^{(\mathrm{I})}$ complexes have played a key role in the design and fabrication of electronic and sensor devices. Recently, the preparation of monomeric five-coordinate $\mathrm{Cu}$-xanthates adducts with pyridine derivatives have been

\section{ARO-The Scientific Journal of Koya University} Volume VI, No 1(2018), Article ID: ARO.10243, 5 pages DOI: $10.14500 /$ aro. 10243

Received 11 May 2017; Accepted: 03 May 2018

Regular research paper: Published 25 May 2018

Corresponding author's e-mail: eman.ibraheem@koyauniversity.org

Copyright (C) 2018 Aeed S. Al-Fahdawi, Eman I. Alsalihi. This is an open-access article distributed under the Creative Commons Attribution License. reported (Gurpreet, et al., 2013). The introduction of pyridyl moiety was to overcome the instability of the fourcoordinate $\mathrm{Cu}$-xanthates complexes (Kour, et al., 2013). In this paper, we describe the synthesis and physical characterization of potassium diphenylmethyl xanthate ligand and its monomeric metal complexes with some of divalent transition metal ions $\left(\mathrm{Fe}^{\mathrm{II}}, \mathrm{Co}^{\mathrm{II}}, \mathrm{Ni}^{\mathrm{II}}, \mathrm{Cu}^{\mathrm{II}}, \mathrm{Zn}^{\mathrm{II}}\right.$, and $\left.\mathrm{Cd}^{\mathrm{II}}\right)$.

\section{EXPERIMENTAL}

\section{A. Materials}

Chemical reagents were commercially available and used without purification (Diphenyl Benzophenone - SigmaAldrich 99\%, Sodium Borohydrate - Merck 99\%, Potassium hydroxide - Sigma-Aldrich 85\%, Carbon Disulfide - Aldrich 99\%, Metal chloride salt - Fluka 98\%, and Methanol - SigmaAldrich 99\%).

\section{B. Physical measurements}

Elemental analyses $(\mathrm{C}, \mathrm{H}, \mathrm{N}$, and $\mathrm{S}$ ) were carried out on a Heraeus instrument (vario EL). Melting points were obtained by a Buchi SMP-20 capillary melting point apparatus. IR spectra were recorded as ATR uses a smart diamond ATR attachment on a Thermo-Nicolet Fourier transform-infrared (FTIR) spectrometer (AVATAR 320) in the range of $4000-500 / \mathrm{cm}$, and as CsI discs using a Shimadzu 8300 FTIR spectrophotometer in the range of $600-300 / \mathrm{cm}$. Electronic spectra were measured between 200 and $1000 \mathrm{~nm}$ with $10^{-3} \mathrm{M}$ solutions in dimethylsulfoxide (DMSO) spectroscopic grade solvent at $25^{\circ} \mathrm{C}$ using a Perkin-Elmer spectrophotometer Lambda. NMR spectra $\left({ }^{1} \mathrm{H},{ }^{13} \mathrm{C}\right.$, DEPT, ${ }^{1} \mathrm{H}-{ }^{-1} \mathrm{H}$ COSY, and ${ }^{13} \mathrm{C}-{ }^{1} \mathrm{H}$ HMQC NMR) were acquired in DMSO-d6 solutions using a Jeol Lambda $400 \mathrm{MHz}$ spectrometer with tetramethylsilane for ${ }^{1} \mathrm{H}$ NMR. Metals were determined using a Shimadzu (A.A) $680 \mathrm{G}$ atomic absorption spectrophotometer. Conductivity measurements were made with DMSO solutions using a Jenway 4071 digital conductivity meter, and room temperature magnetic moments were measured with a magnetic susceptibility balance (Johnson Matthey Catalytic System Division). 


\section{SYNTHESIS}

\section{A. Preparation of diphenylmethanol (Al-Fahdawi and Al-} Salihi, 2015)

The ligand has prepared by dissolving $(1 \mathrm{~g}, 5.51 \mathrm{mmol})$ of diphenyl benzophenone (1.0417 g, $27.55 \mathrm{mmol})$ of sodium borohydride with continues stirring in $50 \mathrm{ml}$ of methanol for $1 \mathrm{~h}$ and then the mixture was treated with microwave for $3 \mathrm{~min}$. The solvent was removed under reduced pressure and the residue was purified using unplait silica gel chromatography with eluent (9.5:0.5 dichloromethane/ methanol) at $R_{\mathrm{f}}=0.8$. Yield: $1.28 \mathrm{~g},(98.1 \%)$, m.p. $63-64^{\circ} \mathrm{C}$. IR (ATR $\left.\mathrm{cm}^{-1}\right)$ characterization was as follows: $3270 \mathrm{v}(\mathrm{O}-$ $\mathrm{H}-\mathrm{O}), 3084 v_{\mathrm{ar}}(\mathrm{C}-\mathrm{H}), 1493$ and1454 $v_{\mathrm{ar}}(\mathrm{C}=\mathrm{C})$. NMR data (ppm), $\delta \mathrm{H}(400 \mathrm{MHz}$, chloroform-D): 7.39-7.25 (m, 10H), $5.83(\mathrm{~s}, 1 \mathrm{H}, \mathrm{OH}), 2.35(\mathrm{~s}, 1 \mathrm{H}, \mathrm{C}-\mathrm{H}) ; \delta \mathrm{C}(100.63 \mathrm{MHz}$, $\left.\mathrm{CDCl}_{3}\right)$ : 76.07, 126.36, 127.47, 128.46, 144.25. X-ray crystallography shows $\mathrm{H}$-atoms were placed in calculated positions $[\mathrm{O} 1-\mathrm{C} 1=1.4348(16), \mathrm{O} 1-\mathrm{H} 1=0.91(2), 1.4348(16)$, $\mathrm{O} 1 \mathrm{~B}-\mathrm{C} 1 \mathrm{~B}=1.4352(15)$, and $\mathrm{O} 1 \mathrm{~B}-\mathrm{H} 1 \mathrm{~B}=0.923(19)]$ and were included in the refinement in the riding model approximation. The yield was $1.28 \mathrm{~g}(98.1 \%)$ of m.p. $63-64^{\circ} \mathrm{C}$.

\section{B. Preparation of xanthate salt}

Xanthate salt was prepared by a conventional method (Seleem, et al., 2011) as in the following: To a suspension of finely powdered (1.1 g, $20 \mathrm{mmol})$, potassium hydroxide was dissolved in $20 \mathrm{ml}$ of dioxane and a solution $(10 \mathrm{mmol})$ of diphenylmethanol and (1.8 g, $24 \mathrm{mmol})$ of carbon disulfide in $10 \mathrm{ml}$ of dioxane was add. The mixture was stirred overnight at room temperature, then $7 \mathrm{ml}$ from diethyl ether was added, and the mixture was stirred for an additional $1 \mathrm{~h}$. A paleyellow solid was collected by filtration, washed with ether, and dried under vacuum. Yield: $1.28 \mathrm{~g}$, (98.1\%) of m.p.= 93-94 ${ }^{\circ} \mathrm{C}$, IR (ATR $\mathrm{cm}^{-1}$ ) characterization was as follows: $3049 v_{\mathrm{ar}}(\mathrm{C}-\mathrm{H}), 1618-1488 v_{\mathrm{ar}}(\mathrm{C}=\mathrm{C})$. NMR data $(\mathrm{ppm}), \delta_{\mathrm{H}}$ (400 MHz, Chloroform-Dme): 7.79-7.47 (m, 10H), 1.62 (s, $1 \mathrm{H}, \mathrm{C}-\mathrm{H}) ; \delta_{\mathrm{C}}\left(100.63 \mathrm{MHz}, \mathrm{CDCl}_{3}\right): 116.33,128.29,129.97$, 132.40, 137.65, 196.40.

\section{General synthesis of the complexes}

A general method was used to obtain the required metallic xanthate complexes as follows:

Metal chloride salt (1 mmole) was dissolved in $10 \mathrm{ml}$ of ethanol and mixed with methanolic solution of the potassium xanthate ligand $(2 \mathrm{mmol})$ in methanol $(15 \mathrm{~mL})$. The mixture was allowed to stir overnight at room temperature, then distilled water was added for precipitating the product. The resulted solid was filtered off, washed by methanol, and dried at room temperature to give the required xanthate complex. Elemental analysis data, colors, and yields for the complexes are given in Table I.

\section{Results AND Discussion}

Free xanthate ligand was obtained from the reaction of diphenyl methanol with carbon disulfide in alkaline medium $(\mathrm{KOH})$. The general synthetic method involves the reaction of some transition metals with alkali metal salt of the corresponding thioacid (exothermic behavior) as shown in Fig. 1.

Xanthate ligand complexes with $\mathrm{Fe}^{\mathrm{II}}, \mathrm{Co}^{\mathrm{II}}, \mathrm{Ni}^{\mathrm{II}}, \mathrm{Cu}^{\mathrm{II}}$, $\mathrm{Zn}^{\mathrm{II}}$, and $\mathrm{Cd}^{\mathrm{II}}$ ions were obtained in a moderate yields. The compounds were characterized by ${ }^{1} \mathrm{H}$ - and ${ }^{13} \mathrm{C}-\mathrm{NMR}$, elemental analysis, IR, UV-Vis, magnetic susceptibility, and conductivity measurements. Diphenylmethanol compound was characterized by IR, thin-layer chromatography (TLC), $\mathrm{X}$-RD powder, ${ }^{1} \mathrm{H}$ - and ${ }^{13} \mathrm{C}-\mathrm{NMR}$ spectra, elemental analysis, and X-ray single crystal diffraction analysis (Al-Fahdawi and Al-Salihi, 2015) (see experimental section).

IR (ATR) spectrum of the ligand shows characteristic bands due to the $v(\mathrm{O}-\mathrm{H})$ and $v(\mathrm{C}=\mathrm{C})$ at $3270 \mathrm{~cm}^{-1}$ and (1493, 1454) $\mathrm{cm}^{-1}$, respectively, as functional groups (Seleem, et al., 2011). ${ }^{1} \mathrm{H}-\mathrm{NMR}$ spectrum for the ligand shows characteristic single peak at $\delta=5.83 \mathrm{ppm}$, which attributed to $\mathrm{O}-\mathrm{H}$ protons. The spectrum displays single resonances at $\delta=2.35 \mathrm{ppm}$ assigned to methanolic group $(\mathrm{C}-H)$. These signals in diphenylmethanol compound are appeared at down filed when they are attached withdrawing groups $\mathrm{CS}_{2}$ to the xanthate salt (Srinivasan, et al., 2012). Whereas IR (ATR) spectrum bands of the xanthate salt ligand show bands at $1618-1488 \mathrm{~cm}^{-1}$ due to $v(\mathrm{C}=\mathrm{C})$ assigned to the aromatic groups, also the spectrum shows band at $1073 \mathrm{~cm}^{-1}$ due to $v(\mathrm{C}=\mathrm{S})$. The disappearance of $v(\mathrm{O}-\mathrm{H})$ band due to the replacement of the hydrogen atom by $\mathrm{CS}_{2}$. The ${ }^{1} \mathrm{H}-\mathrm{NMR}$ spectrum for xanthate salt appears as expected downfield at $\delta=1.62 \mathrm{ppm}$ due to $(\mathrm{C}-\mathrm{H})$ methanolic group and 7.79-7.49, which assigned to aromatic protons (Al-Fahdawi, et al., 2013). The absence of O-H group signal assigned that the $\mathrm{CS}_{2}$ is in attach with oxygen atom. ${ }^{13} \mathrm{C}$-NMR shows important peaks at $\mathrm{CS}_{2}$ which detected at $196.40 \mathrm{ppm}$, which is disappeared in DEPT ${ }^{13} \mathrm{C}$-NMR, because it is quaternary carbon (Al-Fahdawi, et al., 2014; Beer, et al., 2003). That is the metal directed to the desired xanthate complexes. These new complexes were characterized by many techniques such as ATR. The infrared spectra ATR show characteristic bands of ligand and its complexes as shown in Table II.

The important bands of these complexes are ranged about $1230 \pm 15 \mathrm{~cm}^{-1}$ and $1050 \pm 10 \mathrm{~cm}^{-1}$ which are due to the $v(\mathrm{C}-\mathrm{O}-\mathrm{C})$ and $v(\mathrm{C}=\mathrm{S})$ for $\mathrm{Fe}^{\mathrm{II}}, \mathrm{Co}^{\mathrm{II}}, \mathrm{Ni}^{\mathrm{II}}, \mathrm{Cu}^{\mathrm{II}}, \mathrm{Zn}^{\mathrm{II}}$, and $\mathrm{Cd}^{\mathrm{II}}$ metal ion complexes, respectively (Al-Fahdawi and Al-Salihi, 2015). After complexation, the frequency of $v(C-$

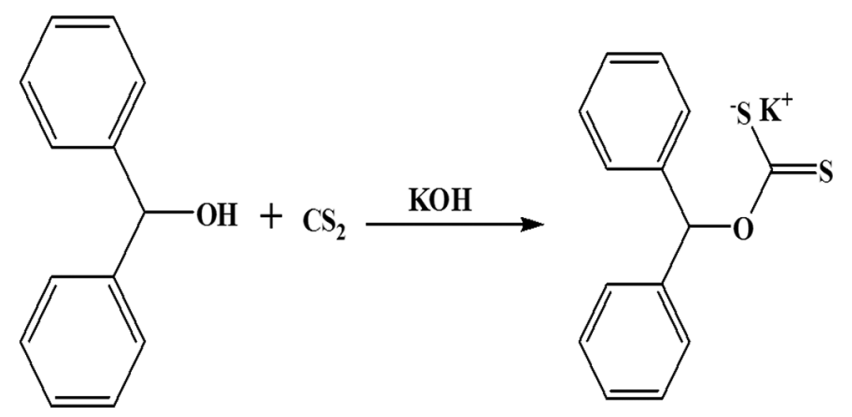

Fig. 1. The synthetic route for ligand and general structure for suggested complexes 
TABLE I

Colors, yields, melting points, (M, C, H, S) ANALysis, and Molar CONDUCTANCE values COMPLeXes

\begin{tabular}{|c|c|c|c|c|c|c|c|c|c|c|}
\hline \multirow[t]{2}{*}{ Molecular formula } & \multirow[t]{2}{*}{ M.Wt } & \multirow[t]{2}{*}{ Weight of yield $g$} & \multirow[t]{2}{*}{ Yield $\%$} & \multirow[t]{2}{*}{ Color } & \multirow[t]{2}{*}{$\mathrm{m} \cdot \mathrm{pc}^{\circ}$} & \multicolumn{4}{|c|}{ Found (calc\%) } & \multirow{2}{*}{$\begin{array}{c}\mathrm{\varepsilon} \mathrm{M}\left(\Omega^{-1} \mathrm{~cm}^{2}\right. \\
\left.\mathrm{mol}^{-1}\right)\end{array}$} \\
\hline & & & & & & M & $\mathrm{C}$ & $\mathrm{H}$ & $\mathrm{S}$ & \\
\hline $\mathrm{C}_{24} \mathrm{H}_{22} \mathrm{O}_{2} \mathrm{~S}_{4} \mathrm{Fe}$ & 526.37 & 0.107 & 54 & Red & $169-171$ & $\begin{array}{c}10.56 \\
-10.54\end{array}$ & $\begin{array}{c}63.8 \\
-63.83\end{array}$ & $\begin{array}{c}4.2 \\
-4.17\end{array}$ & $\begin{array}{c}24.35 \\
-24.31\end{array}$ & 11.3 \\
\hline $\mathrm{C}_{24} \mathrm{H}_{22} \mathrm{O}_{2} \mathrm{~S}_{4} \mathrm{Ni}$ & 529.21 & 0,126 & 63 & Green & $160-161$ & $\begin{array}{c}11.17 \\
-11.09\end{array}$ & $\begin{array}{c}63.52 \\
-63.49\end{array}$ & $\begin{array}{c}4.17 \\
-4.15\end{array}$ & $\begin{array}{c}24.21 \\
-24.18\end{array}$ & 10.9 \\
\hline $\mathrm{C}_{24} \mathrm{H}_{22} \mathrm{O}_{2} \mathrm{~S}_{4} \mathrm{Zn}$ & 535.91 & 0.083 & 41 & White & $151-152$ & $\begin{array}{c}12.27 \\
-12.2\end{array}$ & $\begin{array}{c}62.65 \\
-62.69\end{array}$ & $\begin{array}{l}4.16 \\
-4.1\end{array}$ & $\begin{array}{c}23.91 \\
-23.88\end{array}$ & 13.5 \\
\hline $\mathrm{C}_{24} \mathrm{H}_{22} \mathrm{O}_{2} \mathrm{~S}_{4} \mathrm{Cd}$ & 582.93 & 0,114 & 52 & White & $193-195$ & $\begin{array}{c}19.25 \\
-19.23\end{array}$ & $\begin{array}{c}57.68 \\
-57.63\end{array}$ & $\begin{array}{c}3.8 \\
-3.77\end{array}$ & $\begin{array}{c}21.99 \\
-21.95\end{array}$ & 17.8 \\
\hline
\end{tabular}

TABLE II

FTIR BANDS FOR XANTHATE COMPLEXES

\begin{tabular}{lcccc}
\hline \hline Compound & $\begin{array}{c}v(\mathrm{X}- \\
\mathrm{O}-\mathrm{X})\end{array}$ & $v(\mathrm{X}-\mathrm{O})$ & $v(\mathrm{X}=\Sigma)$ & $v(\mathrm{M}-\Sigma)$ \\
\hline Xanthate & 1235 & 1156 & 1073 & \\
[Fe-Xanthate] & 1223 & 1192 & 1032 & 370 \\
[Co-Xanthate] & 1237 & 1185 & 1038 & 360 \\
[Ni-Xanthate] & 1220 & 1191 & 1050 & 365 \\
[Cu-Xanthate] & 1233 & 1176 & 1068 & 350 \\
[Zn-Xanthate] & 1231 & 1181 & 1059 & 355 \\
[Cd-Xanthate] & 1240 & 1201 & 1061 & 360 \\
\hline \hline
\end{tabular}

FTIR=Fourier transform-infrared

$\mathrm{O}-\mathrm{C})$ and $\mathrm{v}(\mathrm{C}=\mathrm{S})$ bands was shifted to higher and lower frequencies, respectively, for $\mathrm{Fe}^{\mathrm{II}}, \mathrm{Co}^{\mathrm{II}}, \mathrm{Ni}^{\mathrm{II}}, \mathrm{Cu}^{\mathrm{II}}, \mathrm{Zn}^{\mathrm{II}}$, and $\mathrm{Cd}^{\mathrm{II}}$ metal ion complexes indicating that the complexation was carried out through sulfur, which has been confirmed by the frequency of $v(\mathrm{M}-\mathrm{S}) 360 \pm 10 \mathrm{~cm}^{-1}$ (Al-Fahdawi, et al., 2014; Beer, et al., 2003). The analytical data as shown in Table I agree with the suggested formulae $\mathrm{C}_{14} \mathrm{H}_{11} \mathrm{KOS}_{2}$ (Fig. 1). Molar conductance of the complexes in DMSO solutions is indicative of their nonelectrolytic nature ( $\mathrm{Yu}$, et al., 2009). UV-Vis spectra of the $\mathrm{Fe}^{\mathrm{II}}, \mathrm{Co}^{\mathrm{II}}, \mathrm{Ni}^{\mathrm{II}}, \mathrm{Cu}^{\mathrm{II}}, \mathrm{Zn}^{\mathrm{II}}$, and $\mathrm{Cd}^{\mathrm{II}}$ complexes exhibited different extents of red shift of bands related to the ligand field $\pi \rightarrow \pi^{*}$ and $n \rightarrow \pi^{*}$ transitions, bands in the range of $321-450 \mathrm{~nm}$ are related to the charge transfer transition (C.T) (Griffith, et al., 2011; Ma et al., 2011) (Table III).

Magnetic moment value of the $\mathrm{Fe}^{\mathrm{II}}$ complex is in accordance of tetrahedral geometry (Aly, et al., 1985). This has been confirmed by its UV-Vis in DMSO, which displays band in the $d-d$ region at $626 \mathrm{~nm}$, due to ${ }^{5} T_{2} \rightarrow{ }^{5} E$, indicating a tetrahedral structure (Batten and Robson, 1998). The cocomplex displays additional bands in the $d$ - $d$ region at 474 and $670 \mathrm{~nm}$, related to ${ }^{4} A_{2}^{(F)} \rightarrow{ }^{4} T_{2}^{(F)}$ and ${ }^{4} T_{1}^{(F)} \rightarrow{ }^{4} T_{2}{ }^{(F)}$, characteristic for tetrahedral geometry around $\mathrm{Co}^{\mathrm{II}}$ atom (Aly, et al., 1985). Magnetic moment of this complex is typical for tetrahedral structure (Carlucci, et al., 2003). The spectrum of the $\mathrm{Ni}^{\mathrm{II}}$ complex displays band in the $d-d$ region, which is characteristic of square planar complexes. The magnetic moment value of the $\mathrm{Ni}^{\mathrm{II}}$ complex, as well as the other analytical data, is in agreement with its square planar

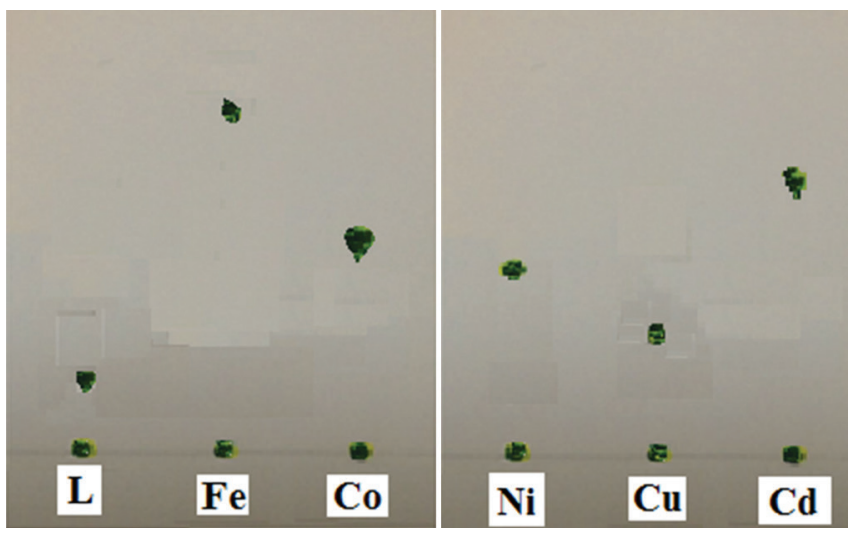

Fig. 2. The thin-layer chromatography measurements for the [L] Ligand and its $\mathrm{Fe}^{\mathrm{II}}, \mathrm{Co}^{\mathrm{II}}, \mathrm{Ni}^{\mathrm{II}}, \mathrm{Cu}^{\mathrm{II}}$, and $\mathrm{Cd}^{\mathrm{II}}$ metal ion

structures (Batten, 2001; Zelenak and Gyoryov, 2002). The $\mathrm{Cu}^{\mathrm{II}}$ complex exhibited electronic spectrum and magnetic moment confirming tetrahedral structure. The electronic spectra of the $\mathrm{Zn}^{\mathrm{II}}$ and $\mathrm{Cd}^{\mathrm{II}}$ complexes exhibited bands related to ligand field and $(L \rightarrow M)$ charge transfer (Lever, 1984). These complexes are diamagnetic as expected ( $d^{10}$ system) and normally prefer tetrahedral coordination. TLC measurement for the derivative ligands [L] and its complexes were performed with $\mathrm{Fe}^{\mathrm{II}}, \mathrm{Co}^{\mathrm{II}}, \mathrm{Ni}^{\mathrm{II}}, \mathrm{Cu}^{\mathrm{II}}$, and $\mathrm{Cd}^{\mathrm{II}}$ are showed in Fig. 2.

The appearance of new spots with different $\mathrm{R}_{\mathrm{f}}$ of $\mathrm{Fe}^{\mathrm{II}}, \mathrm{Co}^{\mathrm{II}}$, $\mathrm{Ni}^{\mathrm{II}}, \mathrm{Cu}^{\mathrm{II}}$, and $\mathrm{Cd}^{\mathrm{II}}$ indicated the formation of the complexes by comparison with the $\mathrm{R}_{\mathrm{f}}$ of the ligand (Table IV).

$\mathrm{X}$-ray powder diffraction (XRD) pattern of Con complex shows well-defined crystalline peaks indicating that the sample is $20 \%$ crystalline in nature (Dokken, et al., 2009), and the XRD powder diffraction pattern of copper complex has been given in Fig. 3.

In Fig. 3, The XRD of $\mathrm{Co}^{\text {II }}$ metal complex of different scale particles is well coincident with each other, and it means that different forms of complexes have the same structure (Guillemet-Fritsch, et al., 2006). The sample has been dried and then scanned in the $2 \theta$ range of $10-80^{\circ}$ confirming four coordination around Co ion complex (Kavitha and Lakshm, 2017; Zheng, et al., 2017). 
TABLE III

UV-VIS MEASUREMENTS AND MAGNETIC MOMENT FOR XANTHATE COMPLEXES

\begin{tabular}{|c|c|c|c|c|c|}
\hline \multirow[t]{2}{*}{ Compound } & Band & Wave number & $\varepsilon_{\max }$ & \multirow[t]{2}{*}{ Assignment } & \multirow{2}{*}{$\frac{\text { Magnetic }}{\text { moment (B.M) }}$} \\
\hline & $\begin{array}{c}\text { Position } \\
\lambda_{\mathrm{nm}}\end{array}$ & $\left(\mathrm{cm}^{-1}\right)$ & $\left(\mathrm{dm}^{3} \cdot \mathrm{mol}^{-1} \cdot \mathrm{cm}^{-1}\right)$ & & \\
\hline [Xanthate] & 261 & 38314 & 1680 & Л $\rightarrow \Omega^{*}$ & \\
\hline \multirow[t]{3}{*}{ [Fe-Xanthate] } & 270 & 37037 & 983 & Intra ligand & 4.5 \\
\hline & 315 & 31746 & 381 & C.T & \\
\hline & 436 & 22936 & 283 & C.T & \\
\hline \multirow[t]{3}{*}{ [Co-Xanthate] } & 257 & 38911 & 1339 & $\pi \rightarrow \pi^{*}$ & 4.2 \\
\hline & 474 & 21097 & 57 & ${ }^{4} \mathrm{~A}_{2}^{(\mathrm{F})} \rightarrow{ }^{4} \mathrm{~T}_{1}^{(\mathrm{p})}$ & \\
\hline & 670 & 14925 & 18 & ${ }^{4} \mathrm{~T}_{1}^{(\mathrm{F})} \rightarrow{ }^{4} \mathrm{~T}_{2}^{(\mathrm{F})}$ & \\
\hline \multirow[t]{3}{*}{ [Ni-Xanthate] } & 266 & 37594 & 880 & $\pi \rightarrow \pi^{*}$ & Diemagnetic \\
\hline & 450 & 22222 & 165 & ${ }^{3} \mathrm{~A}_{2} \mathrm{~g} \rightarrow{ }^{1} \mathrm{~T}_{1} \mathrm{~g}\left({ }^{(\mathrm{P})}\right.$ & \\
\hline & 632 & 15823 & 47 & ${ }^{3} \mathrm{~A}_{2} \mathrm{~g} \rightarrow{ }^{3} \mathrm{~T}_{1} \mathrm{~g}(\mathrm{~F})$ & \\
\hline
\end{tabular}

TABLE IV

The TLC Measurements For the [L] Ligand AND ITS $\mathrm{FE}^{\mathrm{II}}, \mathrm{CO}^{\mathrm{II}}, \mathrm{NI}^{\mathrm{II}}, \mathrm{CU}^{\mathrm{II}}$, AND $\mathrm{CD}^{\mathrm{II}}$ COMPLEXES

\begin{tabular}{lc}
\hline \hline Compound & Range of Rf $(\mathrm{mm})$ \\
\hline Xanthate & 1.2 \\
[Fe-Xanthate] & 4.5 \\
[Co-Xanthate] & 3.1 \\
[Ni-Xanthate] & 2.4 \\
[Cu-Xanthate] & 1.7 \\
[Cd-Xanthate] & 4.0 \\
\hline \hline
\end{tabular}

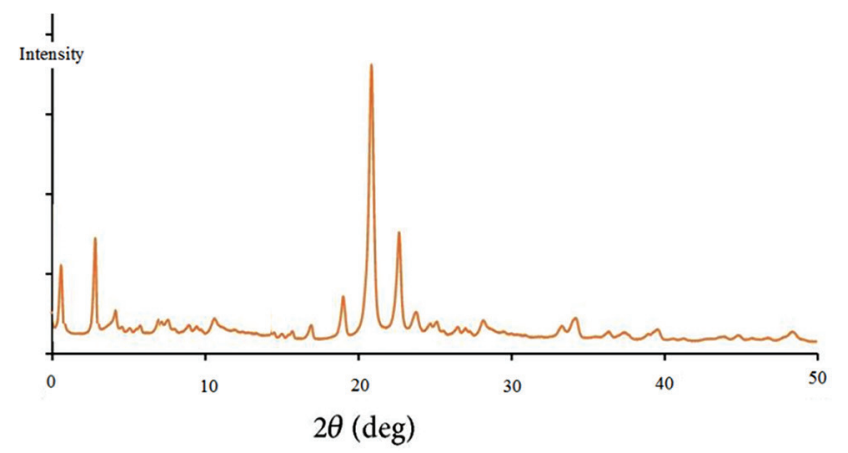

Fig. 3. The X-ray powder diffraction of $\mathrm{Co}^{\mathrm{II}}$ metal complex

\section{CONCLUSION}

In recent years, considerable attention has been devoted to the formation of stable four-coordinate xanthate complexes that consist with CS2 group which have numerous important applications. The reaction of diphenyl methanol with $\mathrm{CS}_{2}$ in alkaline solution gives the required xanthate ligand. It is observed from research data in this study existence of four-coordinated complexes with $\mathrm{Fe}^{\mathrm{II}}, \mathrm{Co}^{\mathrm{II}}, \mathrm{Ni}^{\mathrm{II}}, \mathrm{Cu}^{\mathrm{II}}, \mathrm{Zn}^{\mathrm{II}}$, and $\mathrm{Cd}^{\mathrm{II}}$ metal ions.

\section{REFERENCES}

Al-Fahdawi, A.S. and Al-Salihi, I.I., 2015. Preparation of Tris (diphenyl. methanol) binding by hydrogen bonds through the application of microwave. techniques. International Journal of Current Research in Biosciences and Plant Biology, 2(7), pp.1-9.

Al-Fahdawi, A.S., Al-Kafajy, H.A., Al-Jeboori, M.J. and Potgieter, H., 2014. New bimetallic bisdithiocarbameta-based macrocyclic complex; Preparation and spectral characterization. ChemXpress, 4(3), pp.262-267.

Al-Fahdawi, A.S., Al-Kafajy, H.A., Al-Jeboori, M.J. and Potgieter, H., 2013. Synthesis, spectral and structural studies of neutral co(II), $\mathrm{Ni}$ (II) and $\mathrm{Cu}(\mathrm{II})$ macrocyclic dithiocarbamate- based complexes formed via one pot reaction. Iraq National Journal of Chemistry, 52, pp.414-429.

Aly, M.M., Baghlaf, A.O. and Ganji, N.S., 1985. Linkage isomerism of the oximato group: The characterization of some mono- and binuclear square planar nickel(II) complexes of vicinal oxime-imine ligands. Polyhedron, 4, pp.1301.

Batten, S.R. and Robson, R., 1998. Interpenetrating nets: Ordered, periodic entanglement. Angewandte Chemie International Edition, 37, pp.1460-1494.

Batten, S.R., 2001. Topology of interpenetration. Cryst Eng Commy, 22, pp.6772 .

Beer, P.D., Cowley, A.R., Jeffery, J.C., Paul, R.L. and Wong, W.W. H., 2003. Self-assembled xanthate-transition metal polyether macrocycles and cryptands. Polyhedron, 22(5), pp.795-801.

Carlucci, L., Ciani, G. and Proserpio, D.M., 2003. Polycatenation, polythreading and polyknotting in coordination network chemistry. Coordination Chemistry Reviews, 246, pp.246-247.

Coucouvanis, D., 1979. Progress in Inorganic Chemistry. Vol. 26. John Wiley, New York. pp.302.

Cox, M.J. and Tiekink, E.R.T. 1996. Stnthises and characterization of aryl xanthates of group $12^{\text {th }}$ elements. Kristallog. 211, 111-113.

Dokken, K.M., Parsons, J.G., McClure, J. and Gardea-Torresdey, J.L., 2009. Synthesis and structural analysis of copper(II) cysteine complexes. Inorganica Chimica Acta, 362, pp.395-401.

Exarchos, G., Robinson, S. and Steed, J., 2001. Should solid-state molecular packing have to obey the rules of crystallographic symmetry. Polyhedron, 20, pp.2951.

Griffith, D.M., Szocs, B., Keogh, T., Suponitsky, K.Y., Farkas, E., Buglyo, P. and Marmion, C.J., 2011. Suberoylanilide hydroxamic acid, a potent histonedeacetylase inhibitor: Its X-ray crystal structure and solid state and solution studies of its $\mathrm{Zn}(\mathrm{II}), \mathrm{Ni}(\mathrm{II}), \mathrm{Cu}(\mathrm{II})$ and $\mathrm{Fe}(\mathrm{III})$ complexes. Journal of Inorganic Biochemistry, 105, pp.763-769. 
Guillemet-Fritsch, S., Lebey, T., Boulos, M. and Durand, B., 2006. Dielectric properties of $\mathrm{CaCu} 3 \mathrm{Ti} 4 \mathrm{O} 12$ based multiphased ceramics. Journal of the European Ceramic Society, 26, pp.1245-1257.

Gurpreet, K., Inderjeet, K. and Renu, S., 2013. Synthesis and characterization of the adducts of bis(O-ethyldithiocarbonato)copper(II) with substituted pyridines. International Journal of Inorganic Chemistry, 2013, pp.502856.

Kavitha, N. and Lakshm, P.V.A., 2017. Synthesis, characterization and thermogravimetric analysis of $\mathrm{Co}(\mathrm{II}), \mathrm{Ni}(\mathrm{II}), \mathrm{Cu}(\mathrm{II})$ and $\mathrm{Zn}(\mathrm{II})$ complexes supported by ONNO tetradentdate Schiff base ligand derived from hydrazine benzoxazine. Journal of Saudi Chemical Society, 21, pp.S457-S466.

Kour, G. Kour, I. and Sachar, R. 2013. Synthesis and characterization of the adducts of bis(O-ethyldithiocarbonato)copper(II) with substituted pyridines. International Journal of Inorganic Chemistry, 2013, pp.502856.

Lever,A.B.P., 1984. Inorganic Electronic Spectroscopy. Elsevier Publishing, New York.

Ma, Q., Zhu, M., Lu, L., Feng, S. and Ya, J., 2011. Preparation of molecularly imprinted polymer and its recognition property for salvianolic acid A. Chimica Acta, 370, pp.102-107.

Rao, S.R., 1971. Xanthates and related compounds. Marcel Dekker, New York.
Seleem, H.S., El-Inany, G.A., El-Shetary, B.A. and Mousa, M.A., 2011. The ligational behavior of a phenolic quinolyl hydrazone towards copper (II)-ions. Chemistry Central Journal, 5, pp.2.

Srinivasan, S., Ramalingam, K. and Rizzoli, C., 2012. Synthesis, NMR and single crystal X-ray structural studies on planar NiS4 and NiS2PN chromophores: Steric and electronic effects. Polyhedron, 33, pp.60-66.

Vastag, S., Marko, L., Rheingold, A.L.J. 1990. Pentacoordinate cobalt(III) thiolate and nitrosyl tropocoronand compounds. Organometallic Chemistry, 397, pp.231.

Yu, K., Gu, Z., Ji, R. and Lou, L.S., 2009. Mild oxidation of alkanes and toluene by tert-butylhydroperoxide catalyzed by an homogeneous and immobilized Mn(salen) complex. Tetrahedron, 65, pp.305-311.

Zelenak, V. and Gyoryov, K.D., 2002. Correlation of infrared spectra of zinc (II) carboxylates with their structures. Spectrochim Acta, 8, pp.269.

Zheng, Z., Junwei, X., Sisi, Y., Yangli, C., Yan, W., Zhuo, C. and Chunlin, N., 2017. Two organic cation salts containing tetra(isothiocyanate)cobaltate(II): Synthesis, crystal structures, spectroscopic, optical and magnetic properties. Crystals, 7, pp.92. 